\title{
Compressive Behavior of Steel Members Reinforced by Patch Plate with Welding and Bonding
}

\author{
Xiaoyang Liu1, Mikihito Hirohata² \\ ${ }^{1}$ Department of Civil and Environmental Engineering, Graduate School of Engineering, Nagoya University, Nagoya, Japan \\ ${ }^{2}$ Department of Civil Engineering, Division of Global Architecture, Graduate School of Engineering, Osaka University, Suita, Japan \\ Email: hirohata@civil.eng.osaka-u.ac.jp
}

How to cite this paper: Liu, X.Y. and Hirohata, M. (2018) Compressive Behavior of Steel Members Reinforced by Patch Plate with Welding and Bonding. Open Journal of Civil Engineering, 8, 341-357. https://doi.org/10.4236/ojce.2018.84026

Received: September 6, 2018

Accepted: October 7, 2018

Published: October 10, 2018

Copyright (c) 2018 by authors and Scientific Research Publishing Inc. This work is licensed under the Creative Commons Attribution International License (CC BY 4.0).

http://creativecommons.org/licenses/by/4.0/

\section{(c) () Open Access}

\begin{abstract}
Repair and reinformcement of aged civil steel structures is one of the important issues for maintaining and using them for a long term. For repair and reinforcement of deteriorated civil steel structures due to fatigue and corrosion, patch plate reinforcement is widely applied. Bolting is generally used because of easy quality control and many construction achievements. However, bolting has downsides including holes made and weight increase. Welding is considered to overcome these demerits but in reality the application of welding is unsatisfactory due to the possibility of fatigue crack occurring from the welded part. In this study, a patch plate strengthening system of welded joint assisted with bonding has been proposed. The compressive behaviors of weld-bond jointed specimen were investigated by a series of experiments and FE analysis. It was confirmed that use of welding and bonding was effective to enhance compressive strength of specimen, due to better load-carrying capacity of patch plate compared with sole use of welding.
\end{abstract}

\section{Keywords}

Welding, Bonding, Compressive Behavior, Patch Plate, Reinforcement

\section{Introduction}

One of the major problems confronting steel civil infrastructures such as bridges is deterioration caused by fatigue and corrosion during their design life. The ageing steel bridges generally experience cyclic loading and exposure to severe environment, causing fatigue cracks and plate thickness reduction due to corrosion, which lead to the decrease of load-carrying capacity and even failure of 
structures. Considering the large cost of reconstruction, proper reinforcement and repair on deteriorated members are urgently required to ensure the structure safe and prolong the service time.

The conventional method of repairing or strengthening steel structures is to cut out and replace plating, or attach patch plate to the damaged portion of the member [1]. Replacement is often not feasible due to the difficulties of construction, high expense and long service interruption time; on the contrary, patch plate reinforcement is shown to be effective. The commonly used techniques for applying patch plate are bolting because of easy quality control and many construction achievements. However, increase of self-weight, drilling holes in sound part and weak point for corrosion are significant disadvantages of steel plate bolting. The application of welding has been considered to avoid these demerits, and the features of flexible operation, lightweight, good appearance and tightness make welding a popular joining method. Despite the fact that welding exhibits many strongpoints, in reality patch plate welding is not very satisfactory as it will change the material properties and may lead to fatigue crack occurring from welded part [2].

The main causes of fatigue crack are stress concentration, residual stress, and high applied stress level; some treatments are usually performed to improve fatigue strength, such as TIG-dressing, grinding and hammer peening [3]. Recently adhesive bonding for fiber reinforced polymers (FRP) reinforcement has become a promising joining technology due to lightweight, uniform stress distribution and the elimination of local stress concentrations. As new material for structural rehabilitation in civil engineering, fiber reinforced polymers (FRP) has gained wide acceptance due to the advantages including high strength-to-weight ratios, excellent resistance to corrosion and environmental degradation [4]. However, there is also hesitancy in using bonding technology in structural components, since the long-term strength of adhesive bonding is probably affected by service temperature and environment limitation, such as chemical attacks and the presence of moisture.

As described above, each joining method for patch plate reinforcement has advantages and disadvantages. Therefore, a combination of welding and bonding has been examined for complementing the weak points of each joint method. Weld-bonding, an advanced hybrid joining technology, is generally used for thin plates $(0.5-3 \mathrm{~mm})$ by combining resistance spot welding with adhesive bonding [5]. In recent years it has attracted a great deal of attention of researchers and industries, as a result of the following superior properties of weld-bonded joint: 1) high static strength; 2) long term durability including fatigue performance; 3 ) improved corrosion resistance; 4) excellent appearance [6] [7]. Therefore, weld-bonding has been widely used in many fields such as production and assembly of aircraft, aviation and automobile.

For thick plates in civil steel structures, the possibility of combination of fillet welding and adhesive bonding has been put forward. As the most common type 
of weld for structural steel connections, fillet welding is naturally used for patch plate reinforcement. The concept of the proposed strengthening system is shown in Figure 1. In the case that the steel member reinforced by patch plate with welding is subjected to tensile or compressive force, the stress flows into patch plate from base plate though the welded edges, where stress concentration is anticipated to occur. After introducing adhesive bond material, the two plates are connected by inside bond and edge-side weld beads, the stress can be also transferred to patch plate by bond. Consequently, stress around welded part may be relieved and patch plate carrying load may be increased. Based on this concept, a series of experiments were carried out on patch plate joints by fillet welding assisted with bonding for investigating the static tensile strength and fatigue characteristics [8] [9] [10] [11]. The results of tensile tests on lap joint specimens revealed that the elasticity limit of weld-bond specimens was increased in comparison to that of weld (W) specimens. The 4-point bending fatigue experiment on patch plate joints by the combination of welding and bonding (WB specimens) and by only welding (W specimens) was performed. In comparison to $\mathrm{W}$ specimens, fatigue life of WB specimens was considerably increased when the fatigue cracks occurred at the weld root.

It has been confirmed that the combination of welding and bonding increase the elastic tensile strength and the fatigue strength of patch plate joints. However, a lot of structural components used in civil engineering are subjected to not only tensile and fatigue cyclic loads, but also compressive loads. It is unknown whether the weld-bonded patch plate reinforcement system is effective for the members subjected to compressive loads. Therefore, the compressive behavior of steel members reinforced by patch plate with welding and bonding is focused on in this study. To investigate the effectiveness of weld-bonded patch plate reinforcement system on compression members, a series of experiment and numerical analysis was carried out on box columns with patch plates by welding, bonding and combination of them. Firstly, the materials and specimens used in this study are explained in the $2^{\text {nd }}$ Chapter. Especially, the material properties of bond subjected to weld heat input was examined. Furthermore, the heat affected bond region by welding was estimated in the specimen used in this study. After

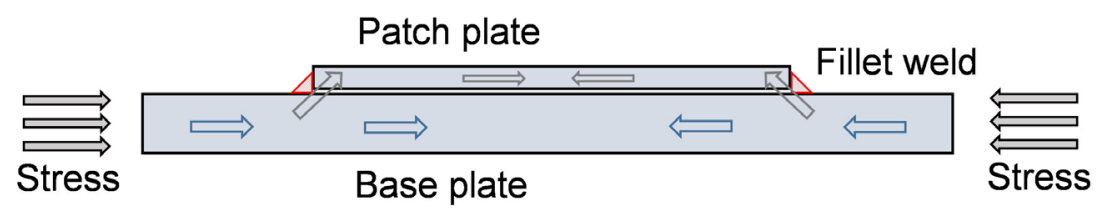

(a)

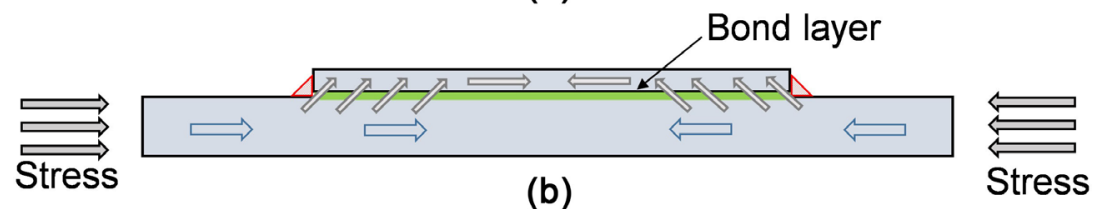

Figure 1. Concept of (a) general patch plate joint and (b) weld-bond patch plate joint systems. 
that, a series of static monotonic compressive experiment was performed in the $3^{\text {rd }}$ Chapter. The purpose of this experiment was to investigate the basic mechanical behavior of box column reinforced by patch plates with the combination of welding and bonding. That is, increase effects of stiffness and compressive strength by the patch plate with the combination of welding and bonding were examined through comparing the specimens with patch plates by solely welding or bonding. Then, the numerical simulation of the compressive experiment was carried out in the $4^{\text {th }}$ Chapter. The purpose of the numerical simulation is for deeper understanding of the mechanism of patch plate reinforcement with the combination of welding and bonding. Finally, the obtained conclusions are summarized in the $5^{\text {th }}$ Chapter.

\section{Materials and Specimen Fabrication}

\subsection{Steel Materials and Specimen}

The purpose of this fundamental research is to investigate the compressive behavior of steel member reinforced by patch plate with welding and bonding. A relatively simple member is suitable for examining its mechanical behavior. Therefore, square box columns with top and bottom plates are selected as the research objects, due to that the boundary condition of panels of box column with top and bottom plates is possible to be assumed as simply supported.

The steel material of box column is STKR 400 of which the width and height are $200 \mathrm{~mm}$, the thickness is $4.5 \mathrm{~mm}$. The top (bottom) plates are SM400A with thickness of $12 \mathrm{~mm}$. Patch plates are general mild steel SPHC with thickness of $1.6 \mathrm{~mm}$. The appearances of box column and patch plate are shown in Figure 2 . The filler metal was mild steel equivalent to JIS Z3312 YGW12 wire of which the diameter is $1.2 \mathrm{~mm}$. Tensile coupons from box column and patch plate are tested in order to determine the mechanical properties. The relationships between stress and nominal strain are shown in Figure 3. Unlike the stress behavior of SPHC, there is no clear yield point in the stress curve of STKR400, due to the cold rolling process during the fabrication of box column, the stress at $0.2 \%$

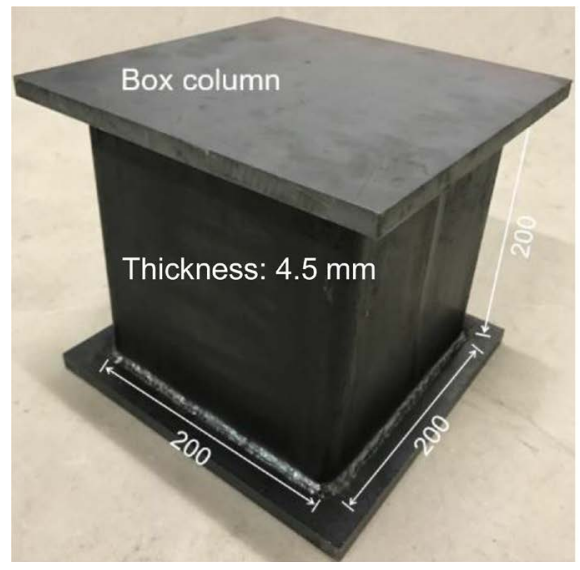

Unit: $\mathrm{mm}$

Figure 2. Appearance of box column specimen and patch plate. 
plastic strain is defined as yield stress. The ultimate stress is referred as tensile strength. The chemical compositions of steel materials and the coupon test results are listed in Table 1, along with the catalogue values of filler metal, top and bottom plates.

\subsection{Adhesive Bond Material}

The adhesive material used is heat-resistant epoxy resin. This kind of bond is mainly used for CFRP or steel patch plate reinforcement bonding in the application of civil structures. In this study, after bonding steel plate to the panel of box column, fillet welding is performed around the edges of plate to process welding and bonding joint. Consequently, the region of bond near the weld bead is possibly affected due to high temperature generated by melting metal. The author investigated the influence of heating on the elastic modulus, the tensile strength, and the tensile lap-shear strength of the epoxy resin [9]. After thoroughly cured

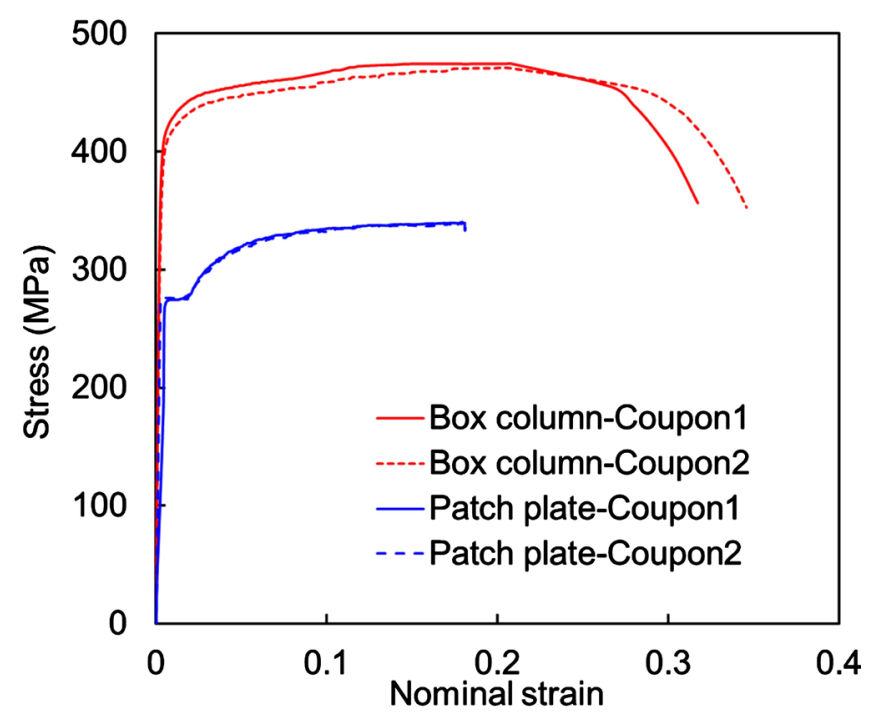

Figure 3. Results of tensile tests on box column and patch plate materials.

Table 1. Chemical compositions and mechanical properties.

\begin{tabular}{cccccccccc}
\hline & \multicolumn{3}{c}{ Chemical compositions (mass\%) } & \multicolumn{3}{c}{ Mechanical properties } \\
\cline { 2 - 8 } Materials & $\mathrm{C}$ & $\mathrm{Si}$ & $\mathrm{Mn}$ & $\mathrm{P}$ & $\mathrm{S}$ & $\begin{array}{c}\text { Yield stress } \\
(\mathrm{MPa})\end{array}$ & $\begin{array}{c}\text { Tensile strength } \\
(\mathrm{MPa})\end{array}$ & $\begin{array}{c}\text { Elongation } \\
(\%)\end{array}$ \\
\hline $\begin{array}{c}\text { Box column: } \\
\text { STKR400 }\end{array}$ & 0.15 & 0.01 & 0.39 & 0.018 & 0.004 & 401 & 474 & 38 \\
$\begin{array}{c}\text { Patch plate: } \\
\text { SPHC }\end{array}$ & 0.12 & 0.01 & 0.60 & 0.015 & 0.005 & 276 & 341 & 18 \\
$\begin{array}{c}\text { Top/Bottom plate: } \\
\text { SM400A }\end{array}$ & 0.14 & 0.17 & 0.62 & 0.025 & 0.006 & 353 & 471 & 28 \\
$\begin{array}{c}\text { Weld metal: } \\
\text { YGW12 }\end{array}$ & 0.09 & 0.44 & 0.96 & 0.012 & 0.012 & 460 & 540 & 31 \\
\hline${ }^{*}$ Catalogue value. & & & & & & & & \\
\end{tabular}


and hardened, the bond material specimens are placed in an electric furnace, heated to $150^{\circ} \mathrm{C}, 200^{\circ} \mathrm{C}, 250^{\circ} \mathrm{C}$ and $300^{\circ} \mathrm{C}$, respectively, and maintained for $15 \mathrm{~min}$. However, the specimens burned and carbonized under the circumstance of $300^{\circ} \mathrm{C}$ in a few minutes. After a cooling process to the room temperature over a period of 2 days, the tests of tensile and shear specimens subjected to $150^{\circ} \mathrm{C}$, $200^{\circ} \mathrm{C}$ and $250^{\circ} \mathrm{C}$ heating, along with the unheated specimens are carried out.

Table 2 shows the test results of bond material. When the test specimen is heated to $150^{\circ} \mathrm{C}$, the elastic modulus exhibits a negligible decrease compared with those without heating. However, in the case that the heating temperature is $200^{\circ} \mathrm{C}$ or $250^{\circ} \mathrm{C}$, the elastic modulus significantly decreases by about $20 \%$. In term of tensile strength and tensile lap-shear strength, the applied heating does not have negative effect on the specimen. Base on the test results, it is known that the mechanical properties of the bond material will be adversely affected and deteriorated when the heating temperature is higher than $150^{\circ} \mathrm{C}$.

To identify the heat-affected bond region due to welding heat input and master the making procedure of joints, the weld-bonded specimens are fabricated by applying patch plate to base plate, instead of box column. The steel of base plate used is SM400A and the dimensions are the same with the panel of box column (width: $200 \mathrm{~mm}$, height: $200 \mathrm{~mm}$, thickness: $4.5 \mathrm{~mm}$ ). The procedure of patch plate attached specimen by welding and bonding is as follows. Initially the surfaces of patch plate and base plate without mill-scale are cleaned by using acetone. After compounding (main agent:hardener $=2: 1$ ) and fully stirring, the adhesive materials (50 $\mathrm{g}$ of epoxy resin) are uniformly smeared on the surface of base plate, then patch plate is placed on the top of bond. After that, pinchers are used to press the patch plate firmly and squeezed out excessive adhesive and inside air, as shown in Figure 4. Finally, fillet welding $\left(\mathrm{CO}_{2}\right.$ semi-automatic welding) is performed around the edges of patch plate after the adhesive has been thoroughly cured and hardened.

The made weld-bonded specimen is cut into pieces to show the appearance of cross section, in order to examine the damage condition of bond layer. The optical microscope photograph showing the region near the weld bead is illustrated in Figure 5. Due to the small thickness of patch plate, the overlapping of weld bead occurred, which may enlarge the high temperature area of bond and reveal negative effect.

As shown in the dotted rectangular in Figure 5, the region of intact adhesive

Table 2. Mechanical properties of bond.

\begin{tabular}{ccccc}
\hline Mechanical properties $(\mathrm{MPa})$ & Not heated & \multicolumn{3}{c}{ Heating temperature $\left({ }^{\circ} \mathrm{C}\right)$} \\
\cline { 3 - 5 } & & 150 & 200 & 250 \\
\hline Elastic modulus $\left(\times 10^{3}\right)$ & 3.8 & 3.7 & 2.9 & 3.1 \\
Tensile strength & 35.7 & 40.0 & 34.2 & 38.4 \\
Tensile lap-shear strength & 29.3 & 32.4 & 32.7 & 32.4 \\
\hline
\end{tabular}



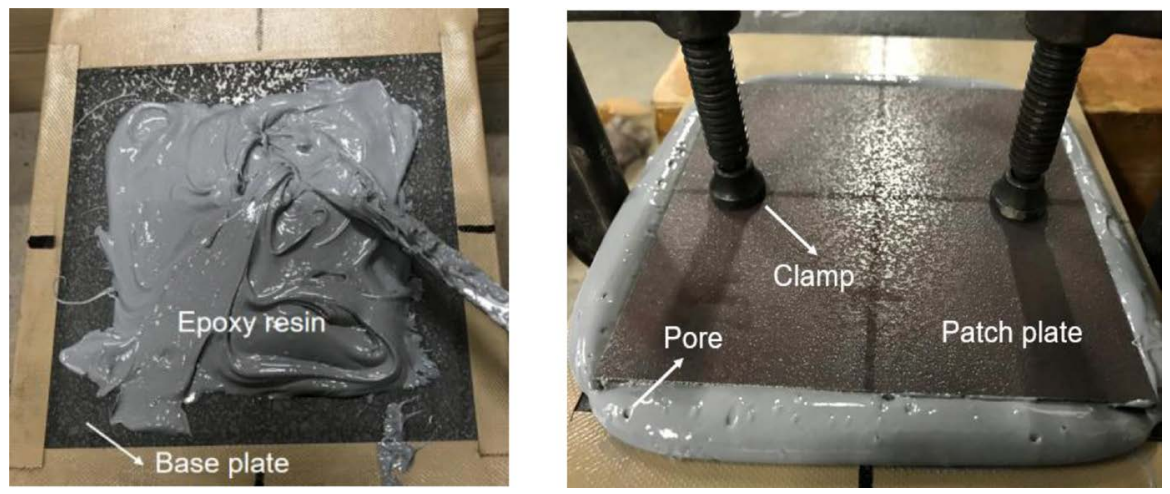

Figure 4. Application of patch plate.

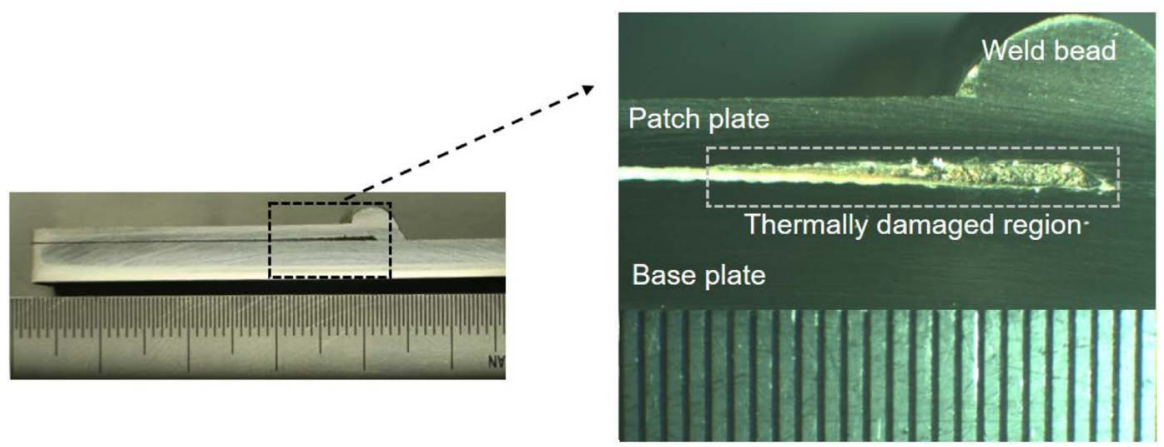

Figure 5. Cross-section of weld-bonded specimen.

exhibits the color of white under a microscope, and the adhesive near the weld root carbonizes and fusional metal fills up this area, where the adhesive is severely damaged. Discoloration of adhesive is also considered as the evidence of influence on bond by welding heat. The rough measurement indicates that the heat-affected region is $9 \mathrm{~mm}$ from the weld root. In addition, the thickness of bond layer is determined by subtracting the thickness of base and patch plate from measured thickness of weld-bonded specimen, $0.2 \mathrm{~mm}$ is the approximate value of bond thickness from measurement and calculation.

On the other hand, a simple thermal conduction theory is applied to carry out the simulation of ultimate temperature in the case that one plate is welded to another. The analysis result is compared with the temperature when bond material property change, that is $150^{\circ} \mathrm{C}$, to examine the region of adhesive affected by welding heat input.

Without consideration of interrelationship of four fillet welds in one specimen, and neglecting the slight effect of bond layer on heating, the highest temperature attainment [12] in case of one single weld bead is calculated by the following equation:

$$
\begin{gathered}
\frac{1}{\theta_{\max }-\theta_{0}}=\frac{1}{\theta_{M}-\theta_{0}}+\frac{r^{2}}{0.234 Q_{n e t} / c \rho} \\
Q_{n e t}=\frac{I U}{v} \cdot \varphi
\end{gathered}
$$


Here, $\theta_{\max }$ is the highest temperature attainment $\left({ }^{\circ} \mathrm{C}\right), \theta_{0}$ is the initial temperature of the plate $\left({ }^{\circ} \mathrm{C}\right), \theta_{M}$ is the melting point $\left({ }^{\circ} \mathrm{C}\right), r$ is the distance from the melting line $(\mathrm{mm}), c$ is the specific heat $(\mathrm{J} / \mathrm{g} \mathrm{K})$ and $\rho$ is the density $\left(\mathrm{g} / \mathrm{mm}^{3}\right) . Q_{n e t}$ is the heat input $(\mathrm{J} / \mathrm{mm})$, expressed by Equation (2), where $I(\mathrm{~A})$, $U(\mathrm{~V}), V(\mathrm{~mm} / \mathrm{s})$, and $\varphi$ represent the current, voltage, speed and thermal efficiency of welding, respectively.

In this experiment, the initial temperature of the plate $\theta_{0}$ is $15^{\circ} \mathrm{C}$. The melting point $\theta_{M}$ is taken to be $1480^{\circ} \mathrm{C}$, the specific heat $c$ is $0.479(\mathrm{~J} / \mathrm{g} \mathrm{K})$ and density $\rho$ is $7.82 \times 10^{-3}\left(\mathrm{~g} / \mathrm{mm}^{3}\right)$. For the welding conditions (current: $120 \mathrm{~A}$, voltage: $20 \mathrm{~V}$, speed: $2.4 \mathrm{~mm} / \mathrm{s}$ ), and taking the thermal efficiency of gas shield arc welding (70\%) into account [13], the heat input $Q_{P}$ is taken to be $700 \mathrm{~J} / \mathrm{mm}$. If the equivalent heat input $Q_{e q}$ flowing into the flange and web of a T-shaped fillet weld, as found in a previous study [14], is the equivalent heat inputs $Q_{B}$ and $Q_{P}$ flowing into, respectively, the base plate and patch plate, $Q_{B}$ and $Q_{P}$ can be found from the following equations:

$$
\begin{gathered}
Q_{B}=Q_{n e t} \cdot \frac{2 t_{B}}{a_{P}+2 t_{B}} \\
Q_{P}=Q_{n e t} \cdot \frac{a_{P}}{a_{P}+2 t_{B}}
\end{gathered}
$$

Here, $t_{B}$ is the thickness of the base plate $(4.5 \mathrm{~mm})$, and $a_{P}$ is the length of the patch plate $(150 \mathrm{~mm})$.

The heat input $Q_{n e t}$ in Equation (1) is substituted by $Q_{B}$ and $Q_{P}$ to result in the maximum temperature $\theta_{\max }$ of base plate and patch plate, the relationship between them and the distance from the weld root is shown in Figure 6, as well as the average value of maximum temperature of base plate and patch plate. It is found that when the distance from the weld root is less than $10 \mathrm{~mm}$, the maximum temperature of patch plate and average value exceed $150^{\circ} \mathrm{C}$. In other words, the bond in the region that the distance from weld root is under $10 \mathrm{~mm}$

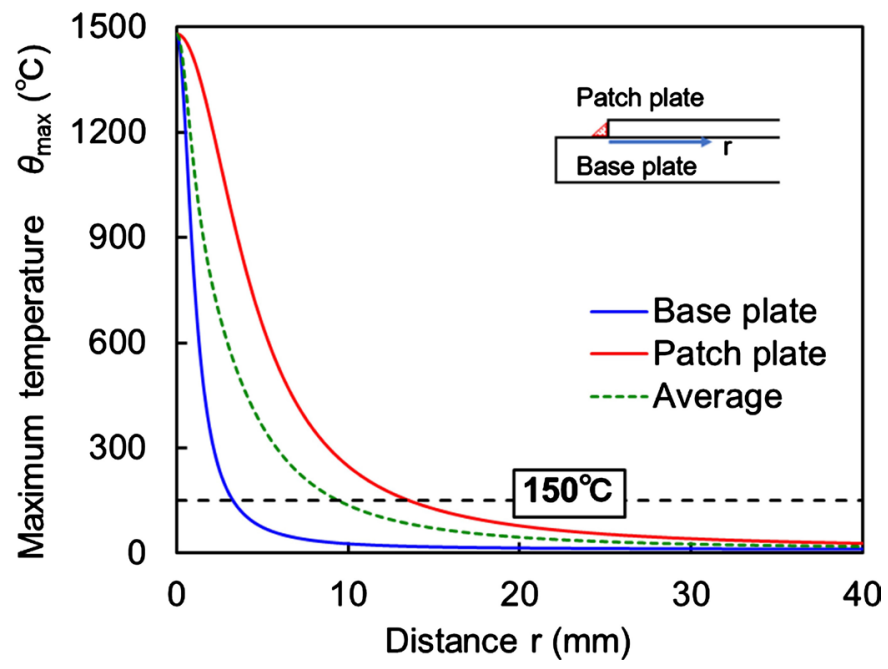

Figure 6. Maximum temperature of base plate and patch plate. 
could be affected by heating, considering of the material characteristic subjected to heating. The estimated result roughly matches the visual observation on the welded-bonded specimen. In fabrication process, it is impossible to control the heat-affected bond region; therefore, the effect of heat-affected bond region on compressive strength of box column will be investigated through numerical analysis.

\subsection{Fabrication Process of Box Column Specimen}

The patch plate jointed specimens for compressive experiment are fabricated by using the steels and bond material described above. In order to eliminate work-hardening and residual stress formed during the process of cold rolling and welding of top and bottom plates, annealing is performed prior to the application of patch plate. First, box columns are heated to $600^{\circ} \mathrm{C}$ and keep 3 hours, following by slow cooling process in furnace. After annealing, the mill scale on the steel surfaces is cleaned by shot blasting. Then, the patch plates are joined by the combination of welding and bonding, welding or the bonding only. The specimens fabricated by welding and bonding are named WB specimens. The specimens are made by only welding or bonding, namely, $\mathrm{W}$ specimens or B specimens, respectively. Furthermore, basic box columns with no patch plate are named $\mathrm{N}$ as control specimens. Two specimens are used for each set of conditions.

\section{Compressive Experiment}

\subsection{Experimental Setup}

A series of static monotonic compressive experiment is performed on the box columns with patch plates joined by welding, bonding and the combination of them. The appearance of loading experiment is shown in Figure 7. Out-of-plane displacements at the center of each panel are measured by four lateral displacement transducers (labeled "DT") installed at mid-height section. Two vertical displacement transducers are also attached to the top plate to measure vertical displacement. Thick steel plates are placed on the specimen, and then static

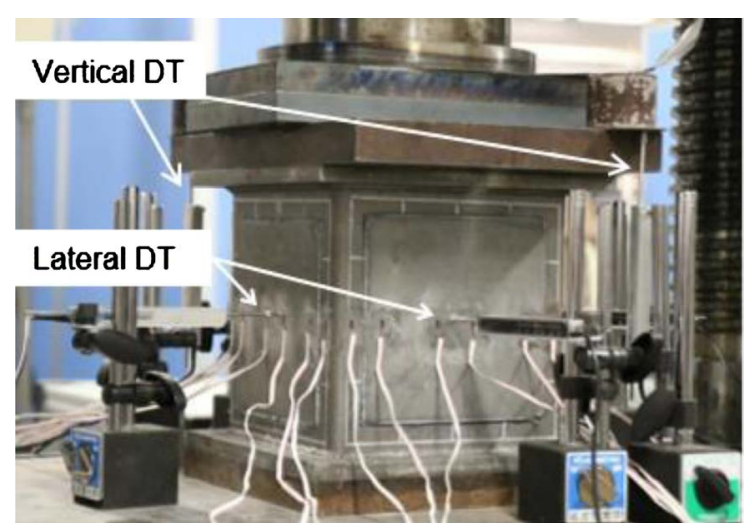

Figure 7. Appearance of loading experiment. 
monotonic compressive load is applied on the specimens using a $2000 \mathrm{kN}$ universal loading machine.

\subsection{Out-of-Plane Displacement Behavior}

The relationships between compressive load and out-of-plane displacement are shown in from Figures 8-11. Panels 1 and 3 are opposite as same as panels 2 and 4. Positive (negative) displacement means outside (inside) deformation of panel. For N, W, and WB specimens, opposite panels exhibit consistent out-of-plane displacement mode, inside or outside. As for B1 specimen, debonding of patch plates on panels 2 and 4 occurred after the ultimate load is reached, as can be seen the sudden increasing displacements from the debonding points in Figure 9(a). The other two patch plates of B1 specimens experience partial debonding along with small inside out-of-plane displacements. This behavior suggests that the middle part of bonded patch plate does not deform with the inside deformation of box column. Partial debonding of the four patch plates is also observed in B2 specimen. The appearances of completed and partial debonding of B specimens are shown in Figure 12. On the other hand, W and WB specimens do not
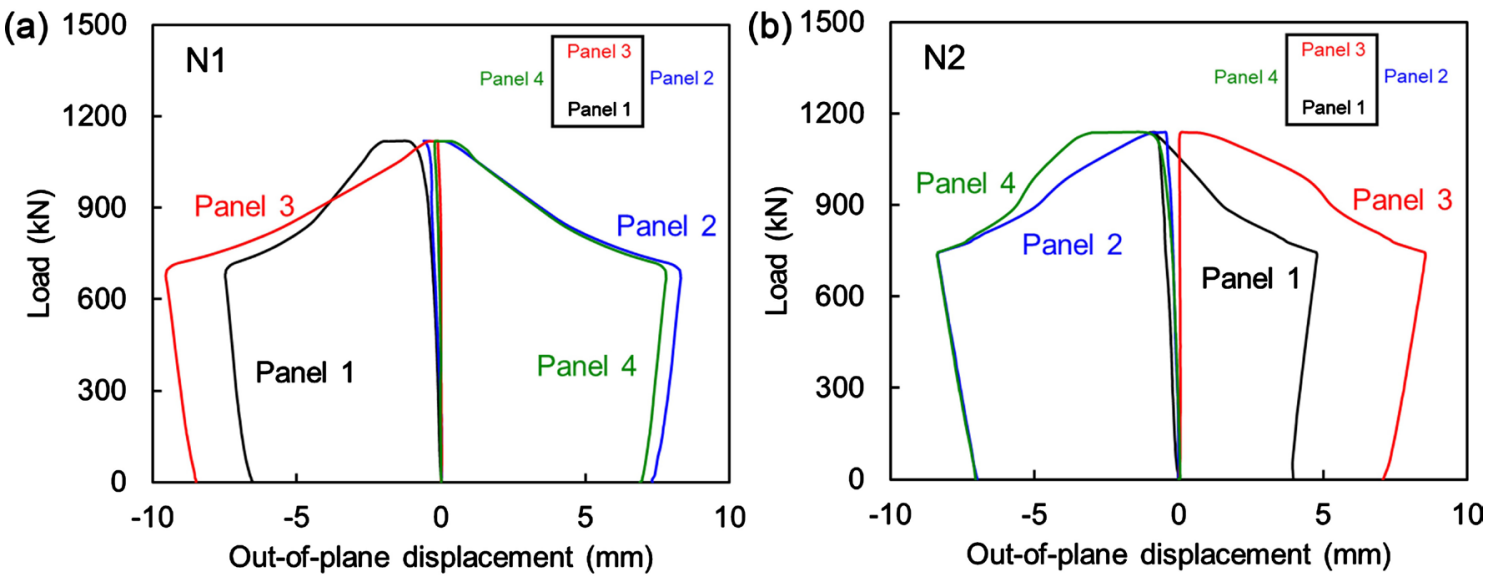

Figure 8. Relationship between load and out-of-plane displacement of (a) N1 and (b) N2 specimens.
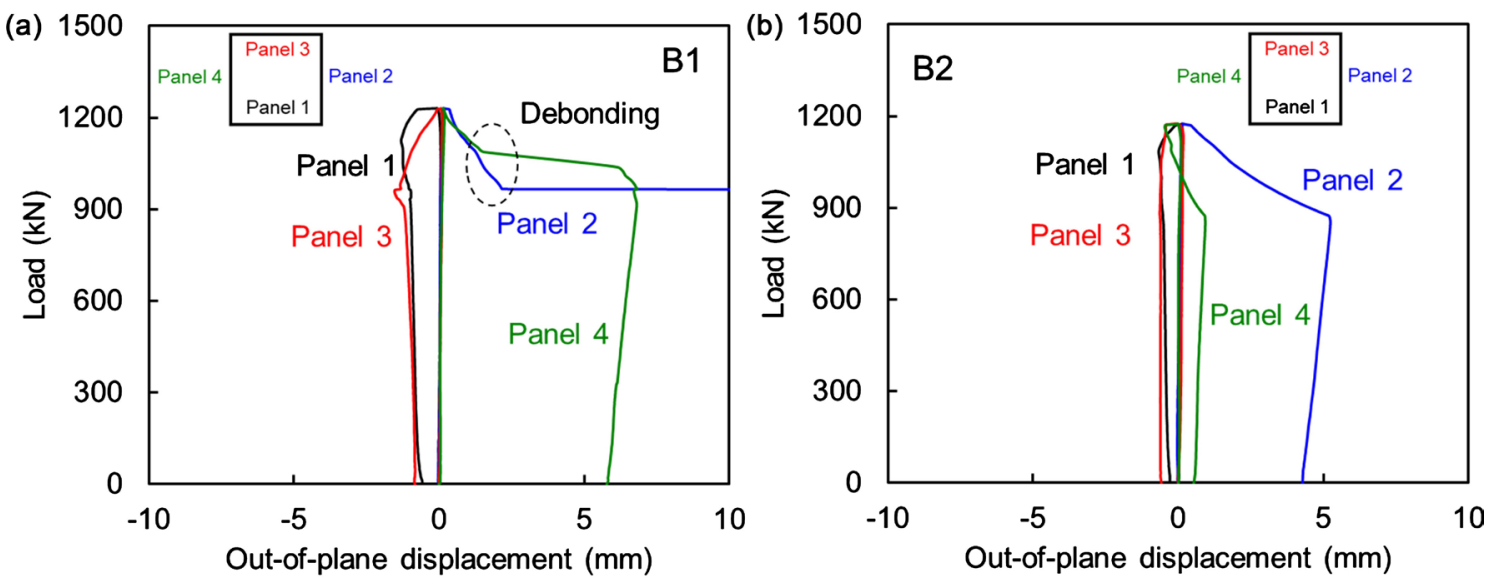

Figure 9. Relationship between load and out-of-plane displacement of (a) B1 and (b) B2 specimens. 

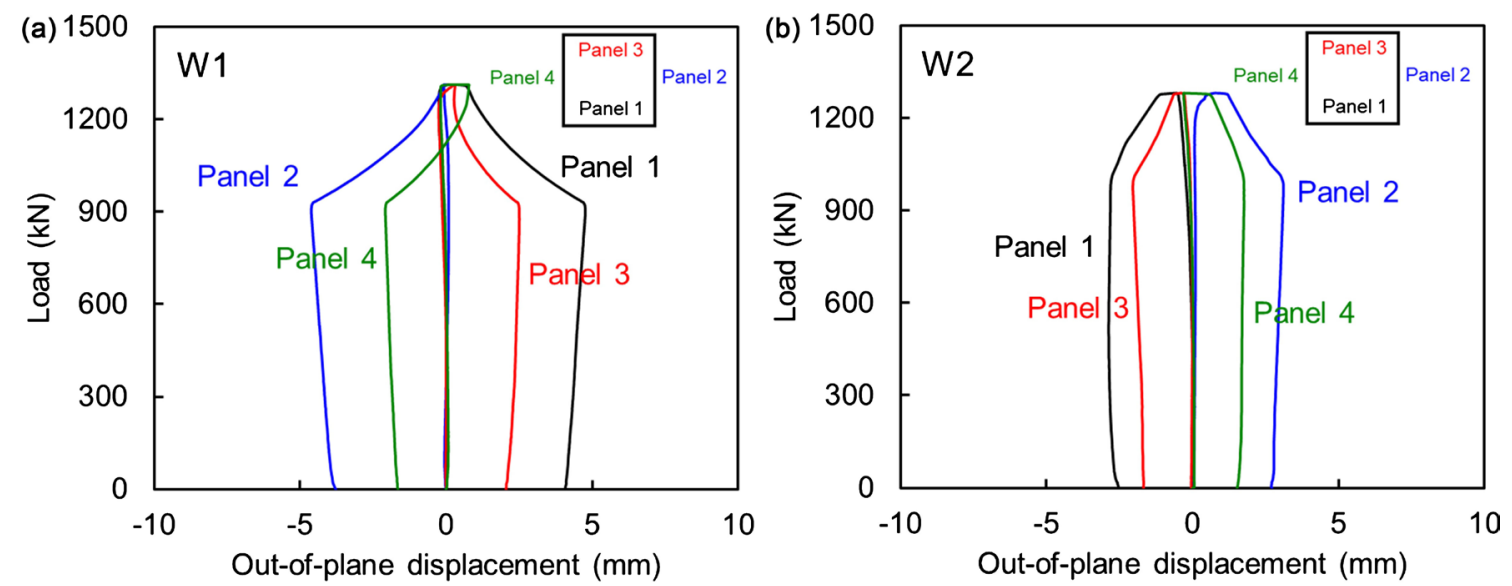

Figure 10. Relationship between load and out-of-plane displacement of (a) W1 and (b) W2 specimens.
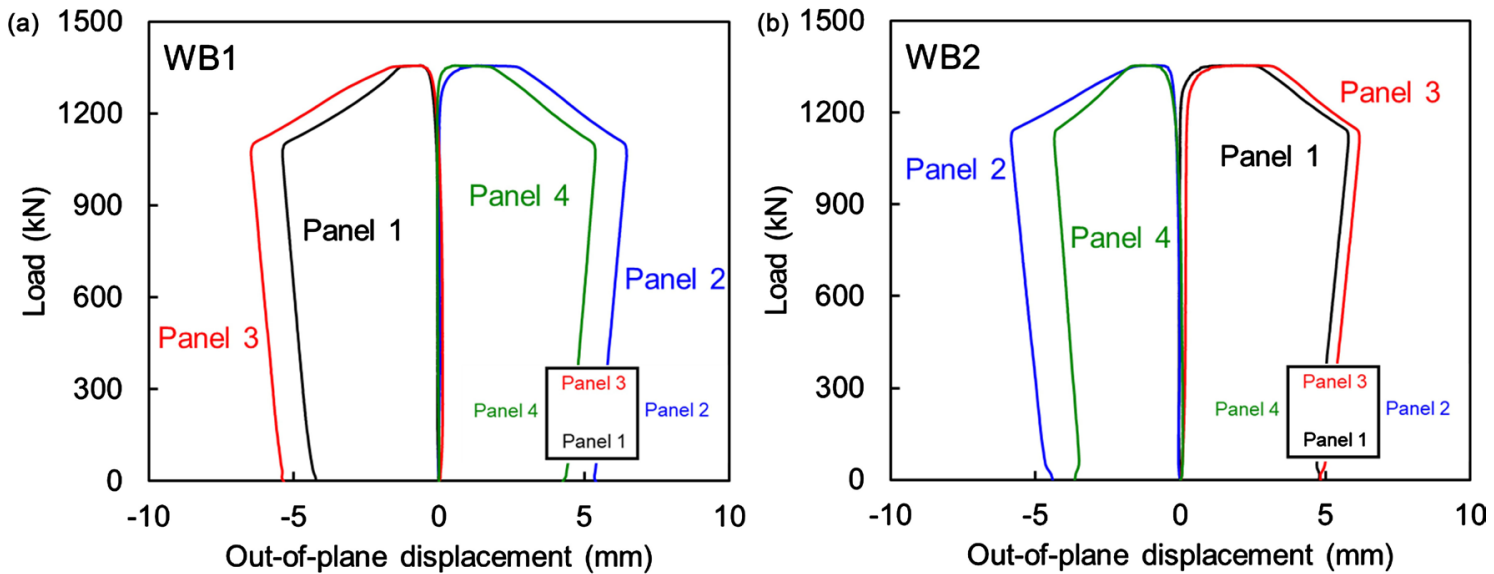

Figure 11. Relationship between load and out-of-plane displacement of (a) WB1 and (b) WB2 specimens.

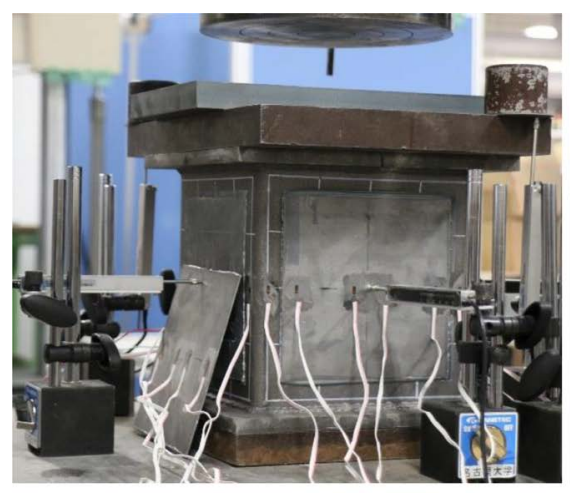

(a)

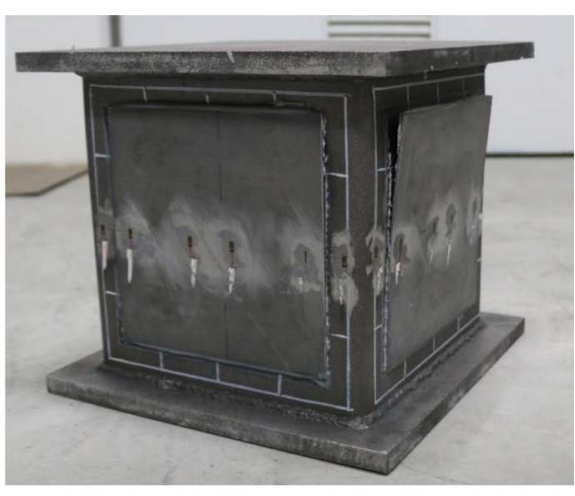

(b)

Figure 12. Patch plate debonding of (a) overall and (b) partial types.

experience debonding of patch plate.

\subsection{Load-Carrying Capacity}

The compressive load-vertical displacement curves of all specimens are shown in Figure 13, in which the two vertical displacement values are obtained by the 


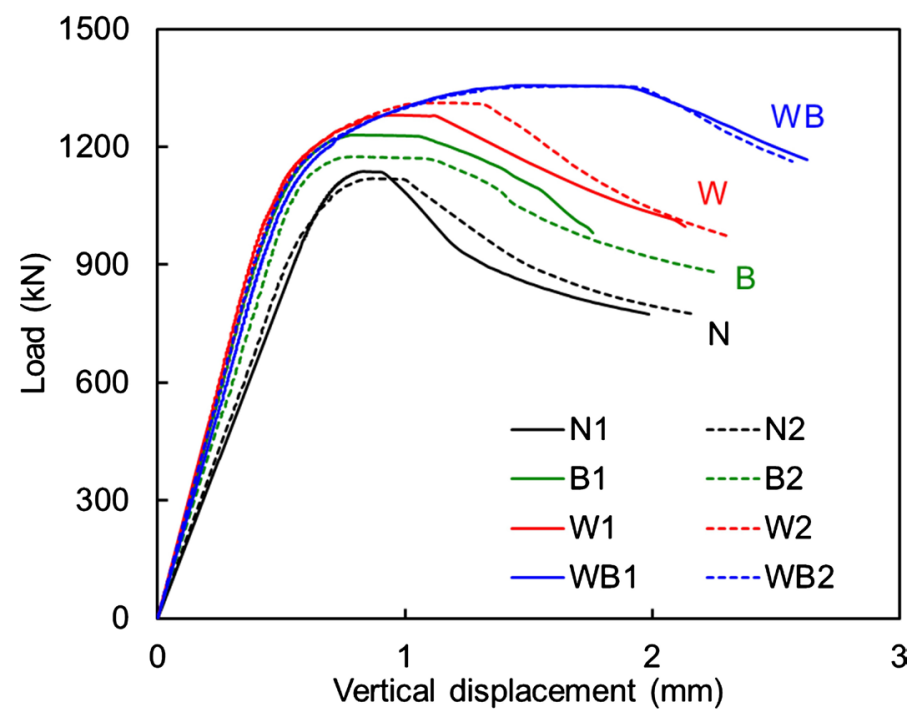

Figure 13. Relationship between load and vertical displacement.

average of the vertical displacement transducers. In elastic stage, the slopes of W, $\mathrm{B}$, and WB specimen curves are larger than those of $\mathrm{N}$ specimens. Therefore, the stiffness increases by attaching patch plates to the surface of box column. Comparing to the un-strengthened control $\mathrm{N}$ specimens, patch plate strengthened specimens by welding, bonding, and welding-bonding could increase the ultimate compressive load up to $14.9 \%, 6.6 \%$ and $20.0 \%$, respectively. The results show that significant compressive capacity improvement of patch plate strengthened box column could be achieved by combination of welding and bonding. It is also observed that the vertical displacements of WB specimens are larger than those of W specimens before the ultimate loads are reached. In other words, WB specimens exhibit better energy absorption ability compared to $\mathrm{W}$ specimens, and the durability could be increased by the existence of bond.

It was confirmed that the ultimate compressive load of box column was increased by joining the patch plates with the combination of welding and bonding. However, it is difficult to examine the effect and mechanism of this combined joint precisely based on the experimental results only. Therefore, numerical simulation is performed in order to gain a better understanding of compressive strength and mechanical behavior of steel members reinforced by patch plate with welding and bonding, numerical analysis is introduced and carried out in next chapter.

\section{Numerical Simulation}

\subsection{Establishment of Models}

The finite element software Abaqus/CAE version 6.14 was used to model the patch plate reinforced box columns, W, B, and WB specimens. Solid element C3D8R is used in the models. To precisely reproduce the compressive behavior of experimental specimens, full elasto-plastic models with top and bottom plates 
were established.

The elastic mechanical properties of steel materials used in the models are elastic modulus and Poisson's ratio, $205 \mathrm{GPa}$ and 0.3 , respectively. The coupon test results and catalogue values are used for plastic mechanical properties of steel materials. Based on the investigation of effect of welding heat input on bond, the bond layer in the region that the distance from weld root is under $10 \mathrm{~mm}$ could be affected by heating. From the viewpoint of conservative design, this region is considered as completely damaged adhesive. Therefore, the mechanical property of intact bond material under the circumstance of room temperature is applied in the models. The elastic modulus is $3.8 \mathrm{GPa}$, and tensile strength is $35.7 \mathrm{MPa}$ (as shown in Table 2). On the other hand, Poisson's ratio of the adhesive bond is 0.35 regardless of the effect of welding heat input. Furthermore, debonding of bond material is not considered here.

In $\mathrm{W}$ and $\mathrm{WB}$ model, welding process is not simulated. Therefore, no welding residual stress is considered. The geometric initial imperfection is not introduced in models.

The assembly of WB model is shown in Figure 14. There is a $0.05 \mathrm{~mm}$ distance between the adjacent surfaces of box column and top or bottom plate, as shown in the figure of cross section, the surfaces are constrained to allow for the interaction, because during loading box column and top or bottom plate are expected to be "hard" contacted. The friction coefficient 0.15 is determined for the tangential behavior of interaction.

Static vertical loading process is created by forced displacement acting on the top plate. The vertical displacement at all nodal points of the bottom plate is fixed. Horizontal rigid body displacement is fixed at specified nodal points.

\subsection{Results of Analysis}

Figure 15 shows the relationship between compressive load and vertical displacement

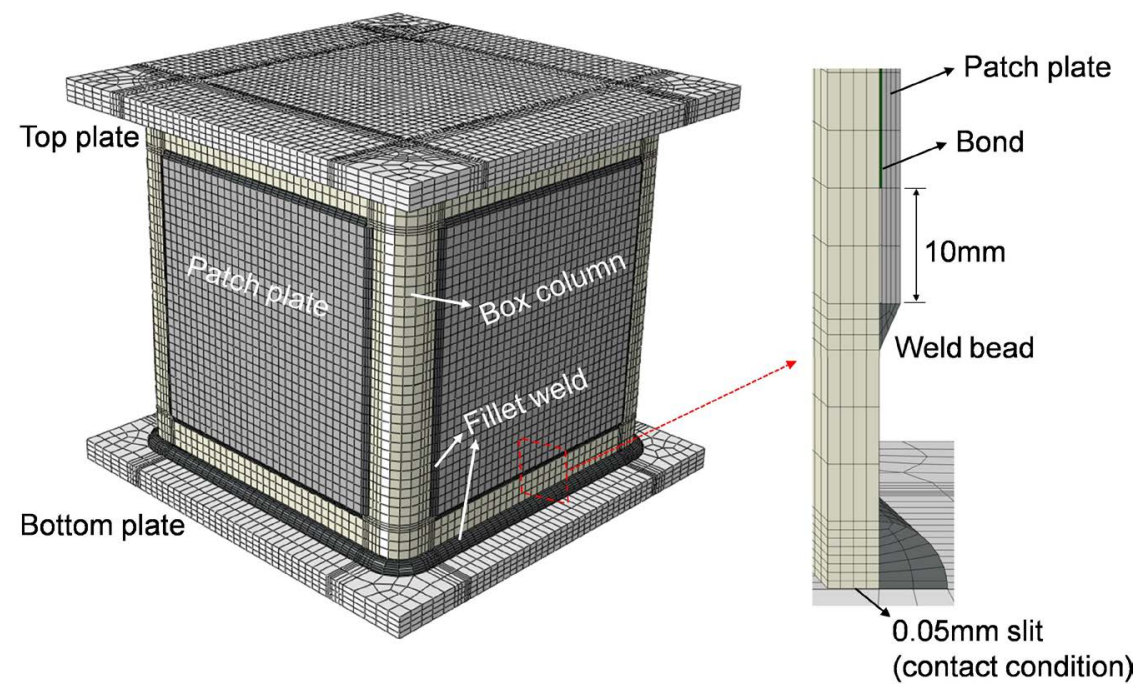

Figure 14. Assembly of WB model. 


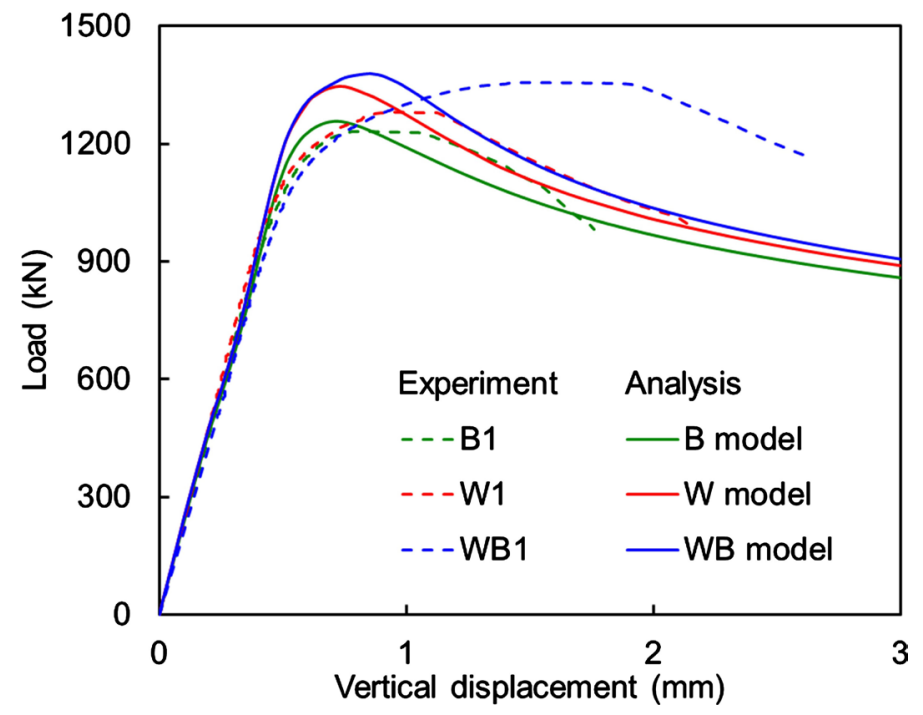

Figure 15. Comparison between experimental and analytical results.

obtained from WB, W and B model. The stiffness and load at ultimate stage of all series agree well with experimental results. However, there are considerable differences of the vertical displacements at ultimate load between analysis and experiment, in the cases of WB and W. In general, welding residual stress largely affects the compressive behavior of steel welded member. The compressive welding stress reduces the elastic limit load of the member. However, the ultimate load was not affected by the welding residual stress [15]. The fillet weld beads are geometrically contacted to box column and patch plate, no heat process is applied in the models, therefore, the residual stresses generated by weld heat input is not considered in the analysis models. Actually, the elastic limit load of WB and W models were lower than those of the experimental results. However, the ultimate strength of them was almost the same as those of experimental results. Furthermore, the load and vertical displacement curve of B model agreed with the experimental result because B model did not include welding residual stress. The results indicated that the reason of difference between the experimental and analytical results of $\mathrm{W}$ and WB model was the ignorance of welding residual stress.

Due to that the objective of this study is to investigate the improvement of the load-carry capacity by patch plate with combination of welding and bonding, the validity of analysis results could be achieved by the established models.

\subsection{Effect of Weld-Bond Combination on Stress Distribution of Patch Plate Joints}

To investigate the load-carrying situation at ultimate load of each series, the Mises stress distributions on the outer surface of box column and patch plate at mid-height are plotted, as given in Figure 16. On box column, the stress of $\mathrm{W}$ and WB model reach yield stress of STKR400 steel although that of B model is lower than yield stress at ultimate load. Similarly, the patch plate of WB model 
yields and the stress exhibits uniform distribution.

In the case of $\mathrm{W}$ model, the region of patch plate in the vicinity of the weld bead yields however, the stress significantly decreases with the increase of distance from weld bead. The results indicate that patch plate jointed by weld bead bears limited load, and combination of welding and bonding could improve the load transfer efficiency thus the joint exhibits better load-carrying capacity. In addition, the stresses of B model are relatively uniform and lower than yield stress.

The influence of welding heat input on bond layer has been discussed in Chapter 2, the heat-affected region is considered as invalid adhesive material. On the other hand, the failure of bond in this study is thought to be strongly related to the occurrence of debonding between bond layer and steel plate. The average shear stresses of bond layer in B and WB model at $800 \mathrm{kN}$ and at ultimate load as shown in Figure 17. The five layers of bond of one panel are selected, as the highlighted nodes in red at mid-height cross section shown in the figure. The shear stress $\tau_{\mathrm{xz}}$ of WB model is lower than that of B model at the same load level. This behavior reveals that the assistance of weld bead can reduce
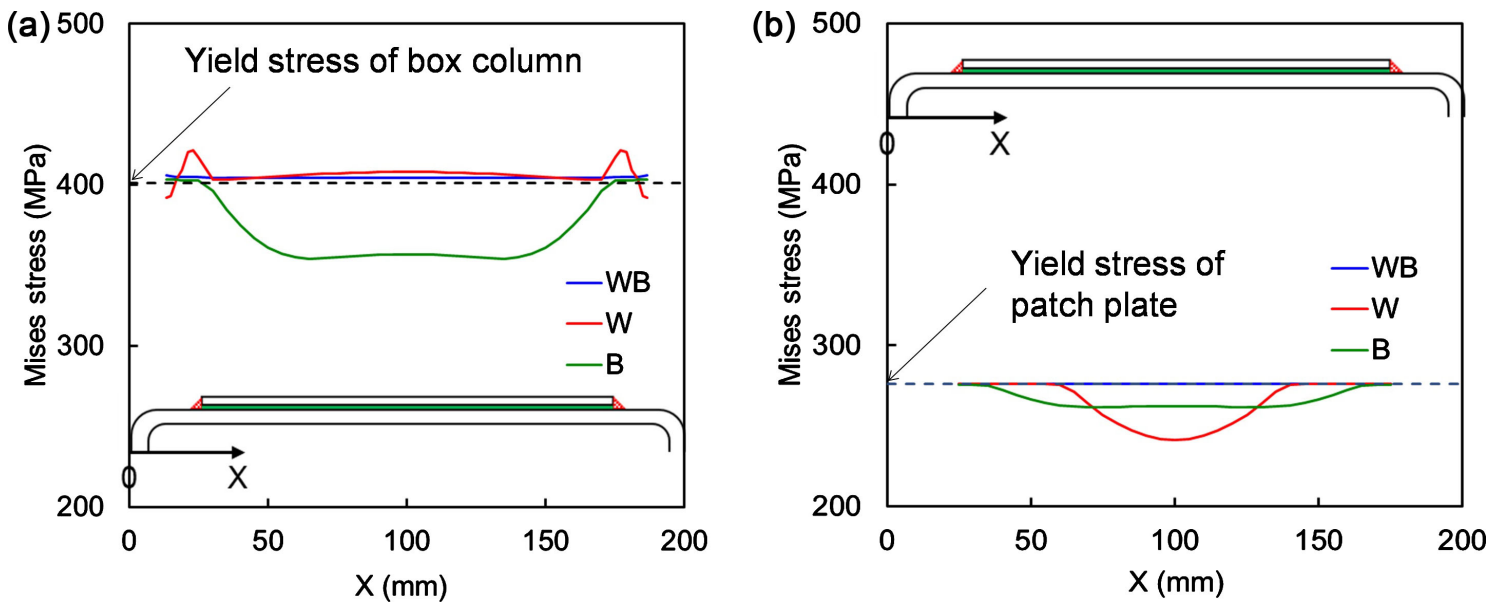

Figure 16. Mises stress distributions on (a) base and (b) patch plate at ultimate load.
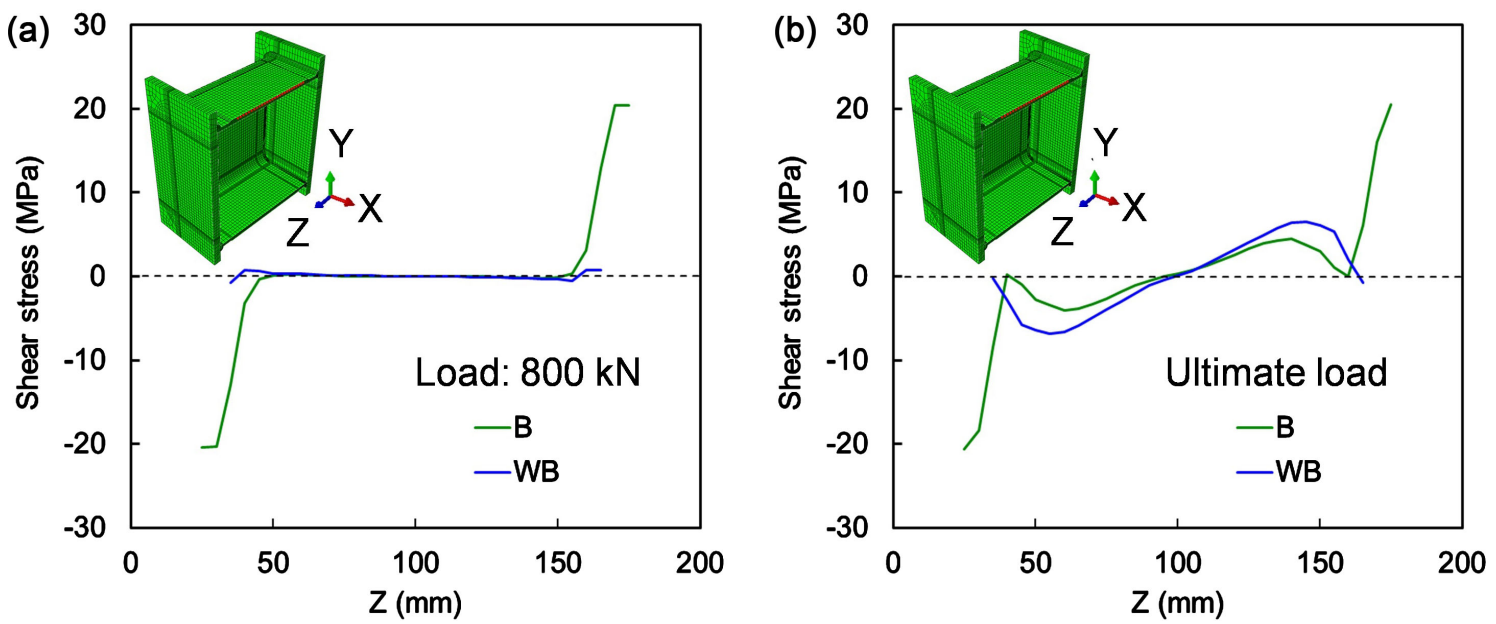

Figure 17. Shear stress distributions of bond layer at load level of (a) $800 \mathrm{kN}$ and (b) ultimate load. 
the shear stress level of bond from the point view of B series, thus prevent the occurrence of debonding.

\section{Conclusions}

This study investigated the compressive behavior of patch plate strengthening system of fillet welded joint assisted with bonding. Box columns reinforced by patch plate with welding only, bonding only, and the combination of welding and bonding (referred to as W, B, and WB specimen) were fabricated. The bond region affected by welding heat input was identified by experimental investigation and thermal conduction theory. After that, a series of experiments were performed on the fabricated specimens. In order to examine the mechanical characteristics of jointed specimens, FEM analysis was carrying out by the established models.

Based on the experimental and analytical results, the following conclusions can be drawn:

1) When the heating temperature generated by welding was higher than $150^{\circ} \mathrm{C}$, mechanical properties of the bond material would be adversely affected. The bond in the region that the distance from weld root was under $10 \mathrm{~mm}$ could be affected by heating under the welding condition in this study.

2) Monotonic compressive loading experiments were performed on N, B, W, and WB specimens. The patch plate of B specimen debonded completely or partially after ultimate compressive load. W and WB specimens didn't experience debonding of patch plate. From the results of compressive experiment, WB specimens exhibited high deformation capacity and compressive strength.

3) The stiffness and ultimate load of W, B, and WB specimen could be reproduced by FE models. The results of FE analysis indicated that patch plate of WB specimen could hold higher load-carrying capacity compared to that of W specimen; thus increase of compressive strength was achieved by the combination of welding and bonding.

4) Shear stress level of the edge of bond layer in WB model was lower than that in B model, because the existence of weld bead could prevent the occurrence of debonding.

This study treated a simple structure as non-stiffened steel box column. The reinforcement effect by patch plate with the combination of welding and bonding on actual structural members such as plate girders, bridge piers and truss members as future work. Then the feasibility of reinforcement work on site should be considered.

\section{Acknowledgements}

A part of this study was supported by research grant of REDAS.

\section{Conflicts of Interest}

The authors declare no conflicts of interest regarding the publication of this paper. 


\section{References}

[1] Zhao, X.L. and Zhang, L. (2007) State-of-the-Art Review on FRP Strengthened Steel Structures. Engineering Structures, 29, 1808-1823. https://doi.org/10.1016/j.engstruct.2006.10.006

[2] Karr, D.G., Douglas, A., Ferrari, C., Cao, T., Ong, K.T., Si, N., He, J., Baloglu, C., White, P. and Parra-Montesinos, G.J. (2017) Fatigue Testing of Composite Patches for Ship Plating Fracture Repair. Ships and Offshore Structures, 12, 747-755. https://doi.org/10.1080/17445302.2016.1222864

[3] Miki, C., Anami, K., Tani, H. and Sugimoto, I. (1999) Methods for Fatigue Strength Improvement by Weld Toe Treatment. Welding International, 13, 795-803. https://doi.org/10.1080/09507119909449006

[4] Teng, J.G., Yu, T. and Fernando, D. (2012) Strengthening of Steel Structures with Fiber-Reinforced Polymer Composites. Journal of Constructional Steel Research, 78, 131-143. https://doi.org/10.1016/j.jcsr.2012.06.011

[5] Fields, D. (1973) Summary of the Weldbonding Process. Adhesives Age, 16, 41-44.

[6] Chang, B., Shi, Y. and Lu, L. (2001) Studies on the Stress Distribution and Fatigue Behavior of Weld-Bonded Lap Shear Joints. Journal of Materials Processing Technology, 108, 307-313. https://doi.org/10.1016/S0924-0136(00)00842-6

[7] Moroni, F., Pirondi, A. and Kleiner, F. (2010) Experimental Analysis and Comparison of the Strength of Simple and Hybrid Structural Joints. International Journal of Adhesion and Adhesives, 30, 367-379. https://doi.org/10.1016/j.ijadhadh.2010.01.005

[8] Hirohata, M. (2015) Static Tensile Strength Characteristics of Fillet Welding Lap Joints Assisted with Bonding. Welding International, 30, 9-17.

[9] Hirohata, M. (2016) Elastic Mechanical Behavior of Spliced Joints Assembled by Fillet Welding and Bonding. Welding in the World, 60, 327-335. https://doi.org/10.1007/s40194-016-0298-8

[10] Hirohata, M. and Itoh, Y. (2018) Fatigue Characteristics of Patch Plate joints by Fillet Welding Assisted with Bonding. Welding International, 32, 243-253.

[11] Hirohata, M. and Itoh, Y. (2016) Fatigue Characteristics of Patch Plate Joints by Fillet Welding Assisted with Bonding. Quarterly Journal of Japan Welding Society, 33, 224-232. (In Japanese) https://doi.org/10.2207/qjjws.33.224

[12] Adams, C.M. (1958) Cooling Rates and Peak Temperatures in Fusion Welding. Welding Journal, 37, 210-215.

[13] Japan Welding Society (2015) Welding and joining Handbook. 2nd Edition, Maruzen. (In Japanese)

[14] Cottrell, C.L.M. (1953) Controlled Thermal Severity Cracking Test Simulates Practical Welded Joints. Welding Journal, 32, 257-272.

[15] Barsan, G.M. and Chiorean, C.G. (1999) Influence of Residual Stress on the Carrying-Capacity of Steel Framed Structures, Numerical Investigation. In: Dubina, D. and Ivany, M., Eds., Stability and Ductility of Steel Structures, Elsevier, Oxford, 317-324. 